\title{
COACHING THE APPLICATION OF AGILE SOFTWARE DEVELOPMENT
}

\author{
Peter Wendorff \\ ASSET GmbH \\ Oberhausen, Germany
}

\begin{abstract}
The success of agile software development has drawn attention to coaching as an alternative management style. In this paper, we argue that coaching, with its focus on trustful relationships, empathetic communication, mental models, and experiential learning, is suitable to facilitate the sustainable application of agile software development.
\end{abstract}

Keywords Agile, management, leadership, coaching

\section{INTRODUCTION}

A central element of the people-centric project management strategy practiced in agile software development (ASD) is coaching. Highsmith (2004, p. 182) characterizes it in the following way: "The objective of coaching and team development is to unleash the capability of the team by helping team members continuously improve their domain knowledge (technical, business), self-discipline, and 'teaming' skills."

The application of eXtreme Programming, currently the most popular agile method, is typically facilitated by a coach. As Beck (2005, pp. 143-144) notes, "A coach is responsible for the process as a whole, keeping the team working at a sustainable pace and continuing to improve. A coach communicates what he sees in such a way that the team can address problems."

This statement highlights a fundamental principle of coaching in ASD: A coach typically identifies issues that might need attention and communicates his perspective to the team, but leaves the responsibility for decisions and their implementation to the team. A coach facilitates, but he does not direct.

Please use the following format when citing this chapter:

Wendorff, P., 2007, in IFIP International Federation for Information Processing, Volume 235, Organizational Dynamics of Technology-Based Innovation: Diversifying the Research Agenda, eds. McMaster, T., Wastell, D., Ferneley, E., and DeGross, J. (Boston: Springer), pp. 519-523. 
Successful coaching results in human growth and encourages independence from the coach. This position is firmly expressed by Beck (p. 144): "Finally, and most importantly, a coach should encourage independence, not dependence. A good coach moves on a little before you think you're ready and leaves behind a team that finds itself firmly on a path to sustainable, profitable, stable, fast, fun software development."

This statement suggests that coaching enables the sustainable application of agile practices.

\section{MANAGEMENT, LEADERSHIP, AND COACHING}

The classical management theorists-Taylor, Fayol, and Weber-viewed managers as commanding and controlling executioners of authority, who use rewards and punishments to direct the behavior of staff. This command-and-control style of management can be very effective in the short run, because it addresses the behavioral level directly, but it often fails to create lasting motivation (Robbins and Coulter 1999).

The famous Hawthorne studies gave rise to the organizational behavior school of thought, which claims that human behavior, driven by emotional and rational factors, is key to understanding organizational phenomena. This school focused much attention on leadership in organizations.

Leaders create an emotionally satisfying social bond with their followers. They use the emotional needs of other people effectively to influence their behavior and inspire followership. Leaders can achieve a high degree of commitment and loyalty among their followers (Bennis 1989). However, strong leadership often results in dependence of followers on their leaders, making organizational performance dependent on a few key leaders (Robbins and Coulter 1999).

In the late 1980 s, there was a growing realization that traditional management and leadership had one common flaw: Frequently, their effects were not lasting, because they mainly focus on direct behavior control rather than change of the underlying mental models (Hudson 1999).

As a reaction to that, coaching became popular as a management style. The key idea was for coaches to work with individuals in order to promote lasting human growth and organizational change by facilitating natural processes of human development in the context of the workplace. In that role a coach acts as a catalyst, or as Hudson $(1999, \mathrm{p}$. 4) writes, "leaven in bread."

Hudson (p. 6) characterizes a coach as

a person who facilitates experiential learning that results in future-oriented abilities....A coach is someone trained and devoted to guiding others into increased competence, commitment, and confidence. The most profound way to learn skills, culture, and values is directly from other human beings who already possess those qualities and who are available to offer guidance and counsel.

Cunningham, Dawes, and Bennett (2001, p. 13) point out that coaching leads to selfmotivation because it focuses on skills of immediate relevance resulting in "the motivation to learn them, the desire to integrate them, and the will to express them in action." 
Coaching achieves lasting results by addressing the level of mental models as drivers of human behavior. Based on a trustful, collaborative working relationship with a coach, mental models are explored, and change is firmly based on increased understanding of perceptions, experiences, and interpretations, resulting in self-motivated learning (Whitmore 2004).

\section{INDIVIDUAL COMPETENCES}

Coaching is a young discipline with a diverse theoretical base (Hudson 1999). Nevertheless, there are some individual competences that are developed in practically every approach to coaching. These competences are shown in Figure 1 as a ramp. The ramp symbolizes how the competences help a person or team to ascend from a given state to a desired state. During that ascent the lower competences support the development of the higher competences. For example, the ability to trust another person is needed before two persons can effectively explore a given situation together. The individual competences are

- Trusting: The ability to establish a collaborative, supportive working relationship, in which sympathy, respect, and care lead to a climate of comfort and safety.

- Exploring: The ability to understand a given problem situation through empathic communication based on dialogue with another person, using structuring techniques like active listening, questioning, and feedback.

- Changing: The ability to identify goals, to develop options for their attainment based on appropriate mental models of reality, and to implement targeted action plans.

- Learning: The ability to adapt own behavior based on a process of emotional and intellectual reflection, insight, and integration.

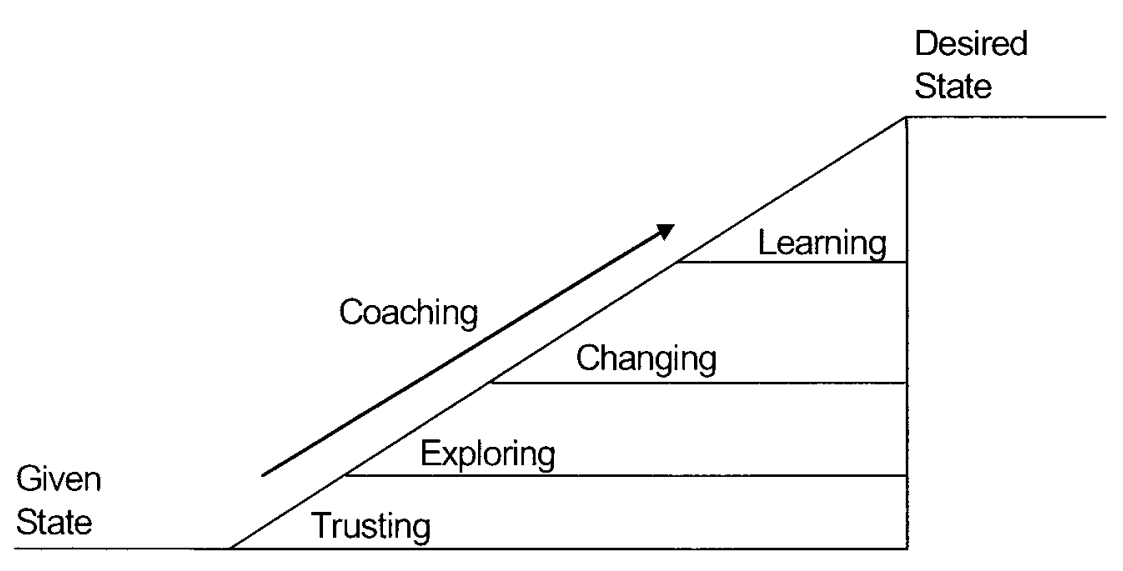

Figure 1. Development of Individual Competences Through Coaching 


\section{RATIONALE BEHIND COACHING}

Coaching is built on two theories: humanistic psychology and experiential learning.

\subsection{Humanistic Psychology}

Humanistic psychology focuses on the mental capacities that enable humans to grow and fulfil their unique potential for responsibility, creativity, and self-determination. It is a value orientation that emphasizes the development of personal competence in the context of social networks.

This approach views the unique mental models held by humans as main drivers of their behavior (Bernstein et al. 2003).

Typical humanistic positions adopted in coaching assume that humans

- can accept responsibility for their lives

- have the inherent capacity to solve problems

- show motivation to engage in satisfying occupations

- want to form mutually satisfying and supporting relationships

- have a lifelong drive to develop in their search for self-actualization

Coaching is critically dependent on social relationships. From the perspective of the humanistic framework it can be described as the relationship-centric use of communication aiming for the facilitation of human growth.

\subsection{Experiential Learning}

A fundamental principle of coaching is learning through own experience (Zeus and Skiffington 2000). The careful observation of own behavior and the conscious experience of its results are an important condition for learning that enables future-orientated adaptation of behavior (Beard and Wilson 2006).

A coach can facilitate experiential learning by

- providing a safe space in which experiences can be shared

- stimulating open and honest reflection on a given situation

- encouraging implementable actions to change a given situation

- facilitating assessment and integration of experiences

Experiential learning naturally includes learning from failure, too. The focus in coaching is not on the avoidance of failure, but rather on learning. Overprotective coaches can become a hindrance to learning (Landsberg 2002).

\section{CONCLUSION}

The application of $\mathrm{ASD}$ represents a challenge for organizations, teams, and individuals. Coaching is a popular way to manage the adoption, application, and evolution of agile processes. 
Coaching differs from more traditional management and leadership significantly in a number of ways. The success of coaching is critically dependent on

- a mutually trustful work relationship

- empathic, structured communication

- change based on realistic mental models

- emotional and intellectual experiential learning

Coaching is firmly based on the values of humanistic psychology and the principles of experiential learning. It shares this theoretical base with ASD and is a bottom-up approach to the application of agile methods, built on democratic involvement and consultation.

A coach only facilitates the application of an agile process and does not make decisions on behalf of others. This encourages motivation, commitment, and a sense of responsibility, that reduces the need for external control by managers or leaders.

Successful coaching encourages self-regulating maintenance processes and increasing independence from the coach over time. This makes it particularly suitable to ensure the sustainable application of ASD.

\section{References}

Beard, C., and Wilson, J. P. Experiential Learning: A Best Practice Handbookfor Educators and Trainers $\left(2^{\text {nd }}\right.$ ed. $)$, London: Kogan Page, 2006.

Beck, K. Extreme Programming Explained: Embrace Change $\left(2^{\text {nd }}\right.$ ed.), Boston: AddisonWesley, 2005.

Bennis, W. On Becoming a Leader, London: Random House, 1989.

Bernstein, D. A., Penner, L. A., Clarke-Stewart, A., and Roy, E. J. Psychology (6 $6^{\text {th }}$ ed.), Boston: Houghton Mifflin, 2003.

Cunningham, I., Dawes, G., and Bennett, B. The Coaching Skill-Builder Activity Pack, New York: AMACOM Books, 2001.

Highsmith, J. A. Agile Project Management, Boston: Addison-Wesley, 2004.

Hudson, F. M. The Handbook of Coaching, San Francisco: Jossey-Bass, 1999.

Landsberg, M. The Tao of Coaching, London: Profile Books, 2002.

Robbins, S. P., and Coulter, M. Management ( $6^{\text {th }}$ ed.), Upper Saddle River, NJ: Prentice-Hall, 1999.

Whitmore, J. Coaching for Performance: GROWing People, Performance and Purpose ( $\left.3^{\text {rd }} \mathrm{ed}.\right)$, London: Nicholas Brealey Publishing, 2004.

Zeus, P., and Skiffington, S. The Complete Guide to Coaching at Work, Sydney: McGraw-Hill, 2000 .

\section{About the Author}

Peter Wendorff holds university degrees in business and engineering. Since 1993, he has been working as an IT consultant in a variety of technical and managerial roles. His professional and academic interests include software engineering, corporate management, organizational theory, humanistic psychology, research methods, and the philosophy of science. Peter can be reached by e-mail at peter.wendorff@integrative-paradigm.com. 